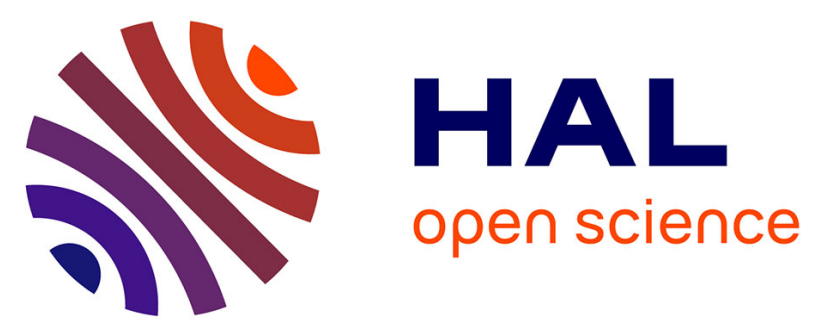

\title{
Desire for a child among HIV-infected women receiving antiretroviral therapy in Cameroon: results from the national survey EVAL (ANRS 12-116)
}

Fabienne Marcellin, Camelia Protopopescu, Claude Abé, Sylvie Boyer, Jérôme Blanche, Pierre Ongolo-Zogo, Sinata Koulla-Shiro, Jean-Paul Moatti, Patrizia Carrieri, Bruno Spire

\section{To cite this version:}

Fabienne Marcellin, Camelia Protopopescu, Claude Abé, Sylvie Boyer, Jérôme Blanche, et al.. Desire for a child among HIV-infected women receiving antiretroviral therapy in Cameroon: results from the national survey EVAL (ANRS 12-116). AIDS Care, 2010, 22 (04), pp.441-451. 10.1080/09540120903202913 . hal-00590593

\section{HAL Id: hal-00590593 https://hal.science/hal-00590593}

Submitted on 4 May 2011

HAL is a multi-disciplinary open access archive for the deposit and dissemination of scientific research documents, whether they are published or not. The documents may come from teaching and research institutions in France or abroad, or from public or private research centers.
L'archive ouverte pluridisciplinaire HAL, est destinée au dépôt et à la diffusion de documents scientifiques de niveau recherche, publiés ou non, émanant des établissements d'enseignement et de recherche français ou étrangers, des laboratoires publics ou privés. 

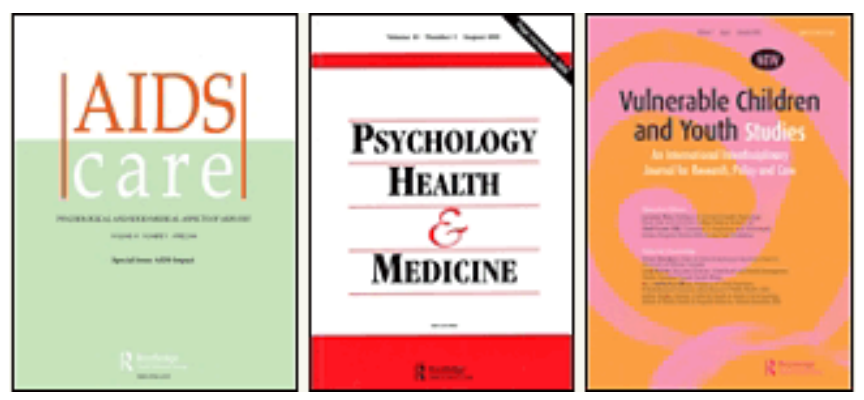

\section{Desire for a child among HIV-infected women receiving antiretroviral therapy in Cameroon: results from the national survey EVAL (ANRS 12-116)}

\begin{tabular}{|r|l|}
\hline Journal: & $\begin{array}{l}\text { AIDS Care - Psychology, Health \& Medicine - Vulnerable Children } \\
\text { and Youth Studies }\end{array}$ \\
\hline Manuscript ID: & AC-2008-12-0580.R1 \\
\hline Journal Selection: & AIDS Care \\
\hline Keywords: & antiretroviral therapy, desire for a child, Africa \\
\hline \multicolumn{2}{|l}{} \\
\hline
\end{tabular}

\section{今 scholaroNE" \\ Manuscript Central}




\section{To Professor Lorraine Sherr, executive director of the AIDS Care Editorial Board}

Dear Pr Sherr,

Thank you very much for giving us the opportunity of submitting a revised version of our paper entitled "Desire for a child among HIV-infected women receiving antiretroviral therapy in Cameroon: results from the national survey EVAL (ANRS 12-116)" to AIDS Care (manuscript ID AC-2008-12-0580, article type: original article).

Please find below the answers to the reviewers' questions and suggestions. We have also enclosed a Microsoft Word version of the revised manuscript.

We hope that this revised version will meet the criteria for publication in your journal, and we remain at your disposal to make any changes which could further improve our manuscript.

With best regards, 


\section{REFEREE(S)' COMMENTS TO AUTHOR:}

\section{REFEREE: 1}

\section{COMMENTS TO THE AUTHOR}

Review - Desire for a child among HIV-Infected women receiving antiretroviral therapy in Cameroon: results from the national survey EVAL (ANRS 12-116)

1- In the abstract and in the conclusion, the authors tell us that "... As a conclusion, the desire to have a child is frequent among ART-treated WLHA in Cameroon. Data suggest that the recovery of health thanks to ART has opened up new life perspectives for these women"...

I think they couldn't confirm this, if they are using the desire to have a child as an indicator of new life perspectives, because they investigated only ART-treated women, and we know, and themselves said in the discussion, that the desire to have a child persist in WLHA, despite HIV infection.

I think it would be very interesting if they had analysed both groups of HIV women, with and without ART-treatment, and compare them. But, it must be too late for this now, so I suggest to the authors to be very careful in their conclusions.

The reviewer is right to underline that our results do not demonstrate any causal relationship between "receiving ART" and "reporting the desire to have a child".

However, we found that, among ART-treated women, those who had a CD4 level below 200 cells $/ \mathrm{mm}^{3}$ at the time of treatment initiation had significantly higher odds of reporting desire for a child than those with higher CD4 level at treatment initiation. Our hypothesis was that women with the most advanced immunodeficiency at treatment initiation may have delayed their pregnancy for health reasons; then, once recovered thanks to ART, may have regained enough confidence in the future to be able to think about positive personal projects, such as pregnancy. This result is partly confirmed by the fact that CD4 level at the time of the survey was not significantly associated with the outcome (result not shown), which suggests that it is the history of severe immunosuppression followed by a substantial recovery rather than the only immunological response to treatment that can give "hope".

However, we agree that this hypothesis may be somewhat hazardous, considering that we only had cross-sectional data, and no information about desire for a child at treatment initiation for instance (this is one of the limitations of our study, that we have described in the "Discussion" section).

As a consequence, we have chosen to remove the following sentence from the "Conclusion" sections of the abstract and manuscript:

"Data suggest that the recovery of health thanks to ART has opened up new life perspectives for these women".

In order to better explain our hypothesis, we have also modified the following sentence in the "Discussion" section of the manuscript:

Original version: 
"On the other hand, the dramatic change in life prognosis thanks to ART has enabled WLHA to take the reins in their lives, especially for those women whose disease is already at a very advanced stage when they initiate therapy."

Revised version:

"On the other hand, women with the most advanced immunodeficiency at treatment initiation may have delayed their pregnancy for health reasons; then, once recovered thanks to ART, may have regained enough confidence in the future to be able to think about positive personal projects, such as pregnancy. This result was partly confirmed by the fact that CD4 level at the time of the survey was not significantly associated with the outcome (result not shown), which suggests that it is a history of severe immunosuppression followed by a substantial recovery rather than the only immunological response to treatment that is likely to revivify WLHA's desire for a child."

2- $\quad$ They defined desire for a child in 4 categories, the third is "I am pregnant", and they considered this as a desire to have a child. I don't agree. To be pregnant not always means desire to have a child. I think it's better to separate them for analyses.

We agree with the reviewer concerning the fact that some pregnancies may be unwanted.

For this reason, in a primary analysis, we grouped pregnant women with women who reported the desire for a child; then, in a sensitivity analysis, we excluded pregnant women from the analysis.

However, we now recognize that the latter approach may be the best in our particular case. Indeed, unfortunately, we have no information about the desire for a child among women who were pregnant at the time of the study, so that we cannot classify them easily into "wanted" or "unwanted" pregnancies (in the survey questionnaire, women were asked if they had the desire to have a/another child, with the possible following answers: (1) yes, I wish I will have a/another child (2) no, I do not want a/another child (3) I am pregnant (4) I cannot have a/another child (infertility, menopause ... etc)).

We have thus decided to exclude pregnant women from our analysis. The text and tables have been modified accordingly (please see revised manuscript for these major changes).

3- They have many results that would be more explored in discussion and even in the conclusion as the other factors significantly associated with desire for a child, and compare them with the literature about desire for a child in women without HIV infection, in order to verify if there are differences between these two populations.

As suggested by the reviewer, we have further explored the impact of economic conditions on women's desire for a child, by comparing our results to the findings of studies among nonHIV-positive women in Asia and Eastern Europe.

To that end, we have added the following sentence to the "Discussion" section:

"Economic factors such as the level of income of the household have also been shown to play a key role in the fertility intentions of women who are not HIV-infected, notably in Eastern Europe and Asia (Mahmood 1992; Ranjan 1999).” 
4- $\quad$ They should give more attention to data about knowledge and beliefs about HIV and $\mathrm{ART}$, and make some suggestions to the services in order to improve information given to their customers.

We agree with the reviewer concerning the importance of taking into account individuals' knowledge and beliefs about HIV, especially in the African context, in order to better tailor the social response to the AIDS epidemic.

As suggested, we have modified the discussion of women's knowledge and beliefs about HIV and we have made some suggestions about the way to improve prevention and counselling. These changes are as follows ("Discussion" section):

Original version:

"Results also showed that better knowledge about HIV and its transmission modes was associated with more frequent report of the desire to have a child, which suggests that women who received information about the disease were better armed to face it. At this point, it must be noted that nearly all women in the present study had integrated fundamental information about HIV (viral cause, main transmission modes, ability of ART to stabilise the development of the disease, risk of mother-to-child transmission), which constitutes an encouraging outcome for the information campaigns conducted in Cameroon."

$\underline{\text { Revised version: }}$

"Results also showed that better knowledge about HIV and its transmission modes was associated with more frequent report of the desire to have a child, which suggests that women who received information about the disease were better armed to face it. At this point, it must be noted that nearly all women in the present study had integrated fundamental information about HIV. Indeed, more than nine women in ten knew about the viral origin of the disease, its main transmission modes (through blood and sexual fluids), the ability of ART to stabilise the development of the disease, and finally, the risk of mother-to-child HIV transmission. Although this constitutes a very encouraging outcome for the information campaigns conducted in Cameroon, there is still much work to do, as some erroneous beliefs go on coexisting with correct basic knowledge and turn out to be detrimental for women's life plans. These are mainly either deeply ingrained popular beliefs (such as belief in the influence of spirits or supernatural forces) or widespread rumour, closely related to both the fear of getting infected and the stigmatization of infected individuals (such as believing that HIV can be transmitted through saliva). In addition, some women still perceive ARV as a curative therapy. These findings highlight the need for developing information and counselling actions on HIV and ART on a regular basis during the follow-up of WLHA, while most information actions are currently conducted at the time of HIV diagnosis and at initiation of ART. These actions should be tailored to the African socio-cultural context. The power of rumour and gossip must be taken into account and used to counteract the distrust and resistance to more formal channels of communication: for instance, community radio broadcasts can be effectively used to spark rumours about HIV containing positive prevention messages (Stadler 2003). In addition, prevention from peers should be maintained and reinforced in HIV care centers, as well as the involvement of HIV-infected people associations in the follow-up of WLHA, in order to pursue the fight against HIV stigma." 
We have also modified the "Conclusion" section of the manuscript as follows:

Original version:

"The desire to have a child is frequent among ART-treated WLHA of reproductive age in Cameroon. Results suggest that recovery of health thanks to ART has opened up new life perspectives for these women. In a national context of the scaling-up of ART, these data suggest that HIV care and family planning programs should be better integrated in order to support WLHA's reproductive choices. Counselling actions should be developed to support WLHA who desire children to maximise their chances to live a healthy pregnancy and to give birth to a HIV-negative baby."

Revised version:

"The desire to have a child is frequent among ART-treated WLHA of reproductive age in Cameroon. Apart from women's reproductive potential (younger age, living in a couple, already being a mother, having frequent sexual relationships), the correlates of this desire comprise, on the one hand, the experience of the HIV disease, through past immunodeficiency and perception of physical HRQL at the time of the survey; and, on the other hand, a good knowledge of HIV and ART. In a national context of the scaling-up of $A R T$, these data suggest that HIV care and family planning programs should be better integrated in order to support WLHA's reproductive choices. Counselling and information actions should be developed on a regular basis throughout women's follow-up. Future prevention strategies should consider alternative channels of communication and should further encourage the involvement of peers in order to support WLHA who desire children, and to maximise their chances to live a healthy pregnancy and to give birth to a HIV-negative baby."

\section{REFEREE: 2}

\section{COMMENTS TO THE AUTHOR}

1. The paper was interesting to read. There are a few suggestions.

2. Chapter - Introduction - may be apart from Africa as a whole, you may want to set out the situation in Cameroon including the socio-economic and demographic situation. Some of the literature review that you have in the Discussion section could also move here as then it sets the rationale of your study.

As suggested by the reviewer, we have added information about the socio-economic and demographic situation in Cameroon in the "Introduction" section, as follows:

"With a HIV prevalence rate of $5.1 \%$ in a total population of more than 18 millions of individuals, Cameroon is among those western and central African countries most affected by the AIDS epidemic (UNAIDS 2008). The management of HIV infection is a great challenge for this country, in which $40 \%$ of individuals live under the poverty line (defined as 20,000 FCFA per equivalent adult and per month) (United Nations Statistics Division 2008) and which is characterized by a very young population (with $48 \%$ of individuals being less than 49 years old) and a high fertility rate (4.5 children per woman) (WHOUNAIDS 2008).” 
In addition, we have moved some sentences from the "Discussion" section to the "Introduction" section of the manuscript, and we have done some modifications in the "Introduction" section, as follows:

Original version:

"Sub-Saharan Africa remains the region most affected by the global AIDS epidemic, with the majority of HIV-infected individuals being women (UNAIDS and WHO 2007). Many of these women are of reproductive age and despite their infection their desire to bear a child remains strong, especially in a social context which considers motherhood as a cornerstone of a woman's identity (Desgrées du Lô̂ and Ferry 2006). Sexual and reproductive health of women living with HIVIAIDS (WLHA) in Africa is given a growing attention [...]"

\section{Revised version:}

"Sub-Saharan Africa remains the region most affected by the global AIDS epidemic, with the majority of HIV-infected individuals being women (UNAIDS \& WHO, 2007). Many of these women are of reproductive age and despite their infection their desire to bear a child remains strong. The persistence of the desire for children despite HIV infection has long been described among women living with HIV and AIDS (WLHA) in Africa (Desgrees du Lô, Msellati et al. 1999; Desgrées du Lô̂ and Ferry 2005; Oladapo, Daniel et al. 2005; Desclaux and Desgrées du Loû 2006; Desgrées du Lô̂ and Ferry 2006; Chama, Morrupa et al. 2007), as an answer to psychological, cultural, economic and social demands (Aka Dago-Akribi, Msellati et al. 2001), in a social context which considers motherhood as a cornerstone of a woman's identity (Desgrées du Lô̂ \& Ferry, 2006). This cultural demand for child-bearing has been confirmed among migrant WLHA native to Africa, in comparison with WLHA native to Europe (Bungener, Marchand-Gonod et al. 2000; Heard, Sitta et al. 2007).

Sexual and reproductive health of women living with HIV/AIDS (WLHA) in Africa is given a growing attention."

3. Chapter - Methods - Was your sample from married or unmarried group? Or both? What was the age group - you say 21 years or older in Patients section and then say fertile women of reproductive age in the Results section. May be if you specify the age range of the participants, this may be clear.

The population analyzed comprised both married and unmarried women. Indeed, among the 1433 women included in the analyses, only $26.3 \%$ were married. This figure appears in Table 1. In the revised manuscript, we have added this information in the "Results" section as follows:

Original version:

"About four women in ten reported they were living in a couple, and half of those included had at least two biological children."

$\underline{\text { Revised version: }}$

"About four women in ten reported they were living in a couple, $26 \%$ were married, and half of those included had at least two biological children."

Concerning the age group, eligibility criteria for participating in the EVAL survey included being aged 21 years or older. However, our analyses focused only on ART-treated women of 
reproductive age ( $<50$ years old) who did not report the inability to have children (and were thus considered as fertile).

For a purpose of clarity, we have modified the last sentence of the "Patients" section as follows:

Original version:

"Our analyses were restricted to those women who participated in EVAL and were receiving ART at the time of the survey."

$\underline{\text { Revised version: }}$

"Our analyses were restricted to fertile women of reproductive age $(<50$ years old) who participated in EVAL and were receiving ART at the time of the survey."

In addition, we have added the age range of the participants in the "Results" section as follows:

Original version:

"Median age [interquartile range 25\%; 75\%, IQR] was 33 [29; 39] years in this population (Table 1)."

Revised version:

"Median age [interquartile range 25\%; 75\%, IQR] was 33 [29; 39] years in this population (Table 1), with a minimum of 21 years old and a maximum of 49 years old."

\section{It would be interesting to know a bit more about the EVAL survey - may be as a footnote?}

The EVAL survey is a research project funded by the French National Agency for Research on AIDS and viral hepatitis (ANRS) which aims at evaluating the national program for improving access to antiretroviral therapy (ART) in Cameroon.

As suggested by the reviewer, we have added the following sentences as a footnote in the "Methods" section:

"The EVAL survey is a research project which aims at evaluating the Cameroonian national program for improving access to ART. It was funded by the French National Agency for Research on AIDS and viral hepatitis (ANRS) and approved by the Ministry of Public Health in Cameroon and the Cameroonian National Ethics Committee."

5. Chapter - Definition of the desire for a child - It is interesting to note that you removed women who could not have a child and you clubbed those who wished to have a child with those who were pregnant. In some papers that I have read, it appears that the pregnancy could be unwanted too. Is it possible to analyse the data with these groups as independent? May be club all those who were currently pregnant and wanted a child with the group which wants a child. It would be interesting to note if there are any differences among these groups. Also, it would be good to know how many women fell in each category. However, it would be interesting to separate out further among the pregnant group how many wanted and how many did not want a child. You performed a Sensitivity test to rule out the unwantedness of the pregnancy and excluded those women from the outcome. I would like to learn more about this test? How does it work? And is really fair to exclude these women from the final analysis does it not give us an understanding of the desire or lack thereof for a child? 
We totally agree with the reviewer concerning the fact that some of the women who were pregnant at the time of the survey may not have deliberately chosen to have a baby. As a consequence, clubbing these pregnant women with those women who did report that they wanted a/another child may result in an overestimation of the number of women who actually desired a child.

For that reason, we performed a sensitivity analysis excluding pregnant women from the population analyzed. Sensitivity analyses are not statistical tests per se but consist in redefining the population analyzed (usually by removing, adding or modifying the classification of a few individuals causing problem) then re-running the final statistical model on this new dataset in order to verify the stability of associations between variables. This is a convenient method to use when a small fraction of the population cannot be easily classified in either category of the outcome of interest. That is the case in our study, in which the 23 pregnant women cannot be easily classified in "desire a child" or "do not desire a child".

Unfortunately, we cannot have information about the number of pregnant women who fall in each of these two categories, as the question about the desire for a child in the survey questionnaire had only 4 possible answers, as follows: (1) yes, I wish I will have a/another child (2) no, I do not want a/another child (3) I am pregnant (4) I cannot have a/another child (infertility, menopause ... etc).

For a purpose of clarity, we have finally decided to exclude pregnant women from the analyses (please see revised manuscript for these in-depth changes in the text and tables).

We have also modified the following sentences in the paragraph describing the study limitations ("Discussion" section):

\section{Original version:}

"Finally, it must be noted that the categories in the outcome variable are not mutually exclusive. Indeed, for instance, a woman who is infertile could wish to have a child, while a woman who is pregnant might not desire to have one. However, for a purpose of homogeneity of the study population, the aim of our analysis was to explore the determinants of the desire for a child among ART-treated fertile women. In this context, the use of a close question to assess women's desire for a child, without allowing multiple answers, was a deliberate choice."

\section{Revised version:}

"In addition, it must be noted that the categories in the outcome variable are not mutually exclusive. In particular, a woman who is infertile could wish to have a child. However, for a purpose of homogeneity of the study population, the aim of our analysis was to explore the determinants of the desire for a child exclusively among fertile women. In this context, the use of a close question to assess women's desire for a child, without allowing multiple answers, was a deliberate choice. Finally, the present study is also limited by the lack of information concerning desire for a child among pregnant women $(n=23)$, who were thus excluded from the analyses".

6. Chapter - Results - Through the paper, would it be possible to round off the percentage for example, $19.4 \%$ could be $19 \%$ and $90.7 \%$ could be $91 \%$. We do see the decimal points in the table - but in the text may be keep it to a rounded off figure?

As suggested by the reviewer, we have rounded all the percentages which appeared in the text. 
7. Chapter - Results (contd.) - The section on socio-economic status- there are some points in the text which are not in the table - for this may be you can say in bracket - not shown in table 1 ? For example - ...nine in ten reported being the only person to contribute to the household income; and another place you say $37 \%$ of women had experienced AIDS defining events what are these events? You also mention women reporting a median of 6 symptoms during the previous four weeks - what are these symptoms? Even in the table you indicate self reported symptoms, general symptoms and lipodystrophy symptoms - for a non-medical person, just a listing would give an indication of what you mean.

As suggested, we have added the mention "not shown in the table" where needed in the "Results" section, as follows:

"Among sexually active women who reported using contraception, the methods most often chosen were condoms (91\% of women) and sexual abstinence or the withdrawal method (15\% of women) (not shown in the table) [...] Forty-one percent reported being the head of their household, and among these nine in ten reported being the only person to contribute to the household income (not shown in the table)."

We used the terms of "AIDS-defining events" to identify the list of conditions used to define the end stage of the HIV disease (CDC stage C), including for instance Kaposi's sarcoma, recurrent pneumonia, and wasting syndrome due to HIV.

In our study, we only had access to information about the patients' clinical stage (CDC C versus $\mathrm{A}$ or $\mathrm{B}$ ), without detailed information about the type of AIDS-defining events that patients had experienced. For a purpose of clarity, we have modified the corresponding sentence as follows:

Original version:

"Thirty-seven percent of women had experienced AIDS-defining events."

$\underline{\text { Revised version: }}$

"Thirty-seven percent of women had experienced AIDS-defining events (CDC stage C)."

The list of self-reported symptoms is as follows:

- general symptoms (derived from the HIV symptom index by Justice et al, J Clin Epidemiol 2001): nausea, vomiting, burning in the stomach, stomach pain, change in the taste of food, bladder or kidney stones, diarrhoea, headache, fatigue, fever, difficulty falling or staying asleep, tickling around the mouth, aching muscles, aching feet and legs (neuropathy), itching skin, hallucinations or dizziness, problems having sexual intercourse and hair or fingernails problems.

- lipodystrophy-related symptoms: change in overall body shape, hollow cheeks, larger belly or wider waist, slimmer arms, slimmer buttocks, slimmer legs, veins on the legs becoming visible, larger breasts, accumulation of fat in the neck.

As suggested by the reviewer, we have given additional indications in the text as follows:

- in the "Variables" section:

Original version: 
"Self-reported symptoms were collected using a 27-item list, which was based on the selfcompleted HIV symptom index developed by Justice et al. (Justice et al, 2001), and included 18 general symptoms often observed during ART (such as headache, fatigue or diarrhea) (Carrieri et al., 2006) and nine other symptoms related to lipodystrophy (Duran et al., 2001).”

\section{$\underline{\text { Revised version: }}$}

"Self-reported symptoms were collected using a 27-item list, which was based on the selfcompleted HIV symptom index developed by Justice et al. (Justice et al, 2001), and included 18 general symptoms often observed during ART (nausea, vomiting, burning in the stomach, stomach pain, change in the taste of food, bladder or kidney stones, diarrhoea, headache, fatigue, fever, difficulty falling or staying asleep, tickling around the mouth, aching muscles, aching feet and legs (neuropathy), itching skin, hallucinations or dizziness, problems having sexual intercourse and hair or fingernails problems) (Carrieri et al., 2006) and nine other symptoms related to lipodystrophy (change in overall body shape, hollow cheeks, larger belly or wider waist, slimmer arms, slimmer buttocks, slimmer legs, veins on the legs becoming visible, larger breasts, accumulation of fat in the neck) (Duran et al., 2001)."

- in the "Results" section:

\section{Original version:}

"Finally, women reported having a median of 6 [3; 9] symptoms during the previous four weeks, and more than nine in ten had physical and mental HRQL score values above 25, on a scale from 0 to 100."

Revised version:

"Finally, women reported having a median of 6 [3; 9] symptoms during the previous four weeks. Fatigue and headache were the general symptoms most often reported (with 59\% and $52 \%$ of women concerned, respectively), while change in overall body shape and larger belly or wider waist were the lipodystrophy-related symptoms most often reported (with $40 \%$ and $22 \%$ of women concerned, respectively) (not shown in the table). In addition, more than nine in ten had physical and mental HRQL score values above 25, on a scale from 0 to 100."

We have also given the detailed list of symptoms as a footnote in Table 1.

8. The data are very interesting and fascinating. But there may be a chance for more in-depth analysis. In the multivariate analysis - may be make an index of socio-economic status, Knowledge and belief about HIV, Modes of transmission and mechanism of action rather than show each variable under each of these titles. I note that in the Discussion chapter, you mention that all women had integrated fundamental information about HIV but in the multivariate analysis you have looked at a few - any particular reason? Creating indices would make the analysis crisper.

We prefer not to sum up the information about women's socio-economic status using a single index, as we think that each variable in this category is interesting to consider in its own. However, we totally agree with the reviewer concerning the advantages of defining indices for the category "Knowledge and beliefs about HIV and ART", including the subcategories "Origin of the disease" (3 questions), "Modes of transmission" (6 questions) and "Mechanisms of action of antiretrovirals" (5 questions). 
We have calculated three aggregate scores, by scoring women's answers to each question ( 1 for a correct answer; 0 for an incorrect or a "do not know" answer), then summing these scores for each subcategory. Consequently, we have obtained a score ranging from 0 to 3 for "Origin of the disease", a score ranging from 0 to 6 for "Modes of transmission", and a score ranging from 0 to 5 for "Mechanisms of action of antiretrovirals", with a higher score denoting better knowledge.

We have added the following sentences in the "Statistical analysis" section of the manuscript:

"Three aggregate scores were calculated to sum up the information concerning women's knowledge and beliefs about the origin of the HIV disease (score ranging from 0 to 3), the modes of transmission of HIV (score ranging from 0 to 6), and finally the mechanisms of action of antiretrovirals (ARVs) (score ranging from 0 to 5). To this end, correct answers were rated 1, while incorrect or "do not know" answers were rated 0 . These rates were then added to obtain the aggregate scores. Higher scores denote better knowledge."

A description of the distributions of these three scores has been added to Table 2 (please see revised manuscript). These data are shown below:

\begin{tabular}{|l|c|}
\hline Aggregate score ... & median [interquartile range] \\
\hline$\ldots$ for "Origin of the disease" & $3[2 ; 3]$ \\
\hline$\ldots$ for "Modes of transmission" & $5[4 ; 6]$ \\
\hline$\ldots$ for "Mechanisms of action of antiretrovirals" & $4[3 ; 5]$ \\
\hline
\end{tabular}

These three aggregate scores were all significantly associated with women's report of desire for a child in univariate analyses, as shown below:

\begin{tabular}{|l|c|}
\hline Aggregate score ... & $\begin{array}{c}\text { Crude odds ratio [95\% confidence interval] } \\
(\mathrm{p}-\text {-valeur })\end{array}$ \\
\hline$\ldots$ for "Origin of the disease" & $1.28[1.13 ; 1.45]$ \\
& $(<0.0001)$ \\
\hline ... for "Modes of transmission" & $1.27[1.17 ; 1.38]$ \\
& $(<0.0001)$ \\
\hline ... for "Mechanisms of action of antiretrovirals" & $1.12[1.02 ; 1.23]$ \\
& $(0.017)$ \\
\hline
\end{tabular}

These data have been added to Table 3 (please see revised manuscript).

In the multivariate analysis, the score for "Origin of the disease" was found to be independently associated with women's report of desire for a child ( $\mathrm{p}=0.008)$. Adjusted odds ratios presented in Table 3 have been modified accordingly (please see revised manuscript).

The following sentence has been added to the "Statistical analysis" section:

"In addition, aggregate scores were entered in the multivariate model, preferably to separate variables for knowledge and beliefs about HIV and ART."

In addition, the following sentence has been added to the "Results" section:

"In addition, a good knowledge about the origin of the HIV disease was also found to be independently associated with women's desire for a child."

Concerning the second point suggested by the reviewer, fundamental information about HIV refers to basic knowledge about the disease, comprising knowledge of the viral origin of the 
disease, of the main transmission modes (unprotected sexual relationships, blood transfusion, mother-to-child transmission) as well as knowledge of the main mechanism of action of antiretrovirals (ie to stabilize the disease).

Our results show that this fundamental information has been well integrated by women, as more than nine women in ten in the study gave the right answers to the corresponding questions, as described in the "Results" section of the manuscript. For that reason, in the original version of the manuscript, we had chosen not to test these variables in the logistic regression models, as explained in the "Statistical analysis" section:

"Each factor was first tested for its association with the desire for a child in a univariate model, excluding categorical variables with classes concerning less than 5\% of individuals."

In the revised version of the manuscript, these variables have been used to calculate the aggregate knowledge scores.

9. Chapter Discussion - This chapter has literature review and this could be moved to the beginning of the paper - as a synopsis. In this chapter, I wonder why have you referred to others who have found similar outcomes - may be just a line saying - our findings confirm or reiterate the outcomes suggested by other researchers and then put everyone's names there and this could be at the end - this would save you words.

Following the reviewer's suggestion, we have tried to simplify the discussion to make it less wordy, and we have added an in-depth discussion of the impact of women's knowledge and beliefs on their desire for a child (please see revised manuscript for these major changes).

10. And finally, the Conclusion chapter seems very weak - you have very interesting findings that have major policy implications - please use those.

Following these suggestions, we have modified the "Conclusion" section as follows:

Original version:

"The desire to have a child is frequent among ART-treated WLHA of reproductive age in Cameroon. Results suggest that recovery of health thanks to ART has opened up new life perspectives for these women. In a national context of the scaling-up of ART, these data suggest that HIV care and family planning programs should be better integrated in order to support WLHA's reproductive choices. Counselling actions should be developed to support WLHA who desire children to maximise their chances to live a healthy pregnancy and to give birth to a HIV-negative baby."

Revised version:

"The desire to have a child is frequent among ART-treated WLHA of reproductive age in Cameroon. Apart from women's reproductive potential (younger age, living in a couple, already being a mother, having frequent sexual relationships), the correlates of this desire comprise, on the one hand, the experience of the HIV disease, through past immunodeficiency and perception of physical HRQL at the time of the survey; and, on the other hand, a good knowledge of HIV and ART. In a national context of the scaling-up of $A R T$, these data suggest that HIV care and family planning programs should be better 
integrated in order to support WLHA's reproductive choices. Counselling and information actions should be developed on a regular basis throughout women's follow-up. Future prevention strategies should consider alternative channels of communication and should further encourage the involvement of peers in order to support WLHA who desire children, and to maximise their chances to live a healthy pregnancy and to give birth to a HIV-negative baby." 
Desire for a child among $\mathrm{HIV}$-infected women receiving antiretroviral therapy in Cameroon: results from the national survey EVAL (ANRS 12-116)

Abstract word count: 260

Text word count: 3786 


\section{ABSTRACT}

The majority of HIV-infected people in sub-Saharan Africa are women, many of reproductive age. Cameroon is severely hit by the AIDS epidemic and has developed a large national program for improving access to antiretroviral treatment (ART). The reproductive intentions of women living with HIV/AIDS (WLHA) who obtain access to ART in this country remain poorly documented. Our study aimed at exploring factors associated with the desire to have a child among 1,433 ART-treated fertile WLHA aged <50. Analyses were based on data collected during the national cross-sectional survey EVAL (ANRS 12-116), which was conducted between September 2006 and March 2007 in 27 HIV care centers in Cameroon. Logistic regression was used to explore factors associated with women's desire to have a child, defined as reporting the wish to have a/another child.

A total of 791 women (55\%) reported the desire to have a child. After adjusting for age, matrimonial status, number of biological children and sexual activity, the main factors independently associated with this desire in a multivariate analysis were having a good physical health-related quality of life (HRQL) (1.02[1.01-1.03] for a one-point increment on the SF-12 scale) and a CD4 count at ART initiation $<200$ cells $/ \mathrm{mm}^{3}(1.7[1.2-2.4])$. As a conclusion, the desire to have a child is frequent among ART-treated WLHA in Cameroon. HIV care and family planning programs should be integrated more thoroughly in order to support WLHA's reproductive choices.

Keywords: antiretroviral therapy; desire for a child; Africa. 


\section{INTRODUCTION}

Sub-Saharan Africa remains the region most affected by the global AIDS epidemic, with the majority of HIV-infected individuals being women (UNAIDS and WHO 2007). Many of these women are of reproductive age and despite their infection their desire to bear a child remains strong. The persistence of the desire for children despite HIV infection has long been described among women living with HIV and AIDS (WLHA) in Africa (Desgrees du Loû, Msellati et al. 1999; Desgrées du Loû and Ferry 2005; Oladapo, Daniel et al. 2005; Desclaux and Desgrées du Loû 2006; Desgrées du Loû and Ferry 2006; Chama, Morrupa et al. 2007), as an answer to psychological, cultural, economic and social demands (Aka Dago-Akribi, Msellati et al. 2001), in a social context which considers motherhood as a cornerstone of a woman's identity (Desgrées du Loû and Ferry 2006). This cultural demand for child-bearing has been confirmed among migrant WLHA native to Africa, in comparison with WLHA native to Europe (Bungener, Marchand-Gonod et al. 2000; Heard, Sitta et al. 2007).

Sexual and reproductive health of WLHA in Africa is given a growing attention ${ }^{1}$. However, while many African countries have initiated national programs to improve access to antiretroviral therapy (ART) and HIV care, the determinants of the reproductive intentions of WLHA who obtain access to ART in a scale-up context are still poorly documented (Myer, Morroni et al. 2007; Kaida, Maier et al. 2008; Mokgatle-Nthabu, Chinkanda et al. 2008).

With a HIV prevalence rate of $5.1 \%$ in a total population of more than 18 millions of individuals, Cameroon is among those western and central African countries most affected by the AIDS epidemic (UNAIDS 2008). The management of HIV infection is a great challenge for this country, in which $40 \%$ of individuals live under the poverty line (defined as 20,000 FCFA per equivalent adult and per month) (2008) and which is characterized by a very young population (with $48 \%$ of individuals being less than 49 years old) and a high fertility rate (4.5

\footnotetext{
${ }^{1}$ Resources for HIV/AIDS and Sexual and Reproductive Health Integration site, http://www.hivandsrh.org/
} 
children per woman) (WHO-UNAIDS 2008). In 2001, Cameroon initiated a large national program to improve access to ART, based on the decentralisation of HIV care. In June 2007, about $48 \%$ of patients eligible for HIV treatment in the country benefited from ART (National AIDS Control Committee 2007). We used data collected in 2007 from a large sample of HIVinfected individuals in Cameroon to explore the socio-economic, clinical and psychosocial characteristics associated with the desire to have a child among ART-treated fertile WLHA of reproductive age in this country.

\section{METHODS}

\section{Patients}

This study is based on data collected during the national cross-sectional multicenter survey EVAL (ANRS 12-116) ${ }^{2}$ which was conducted in Cameroon between September 2006 and March 2007, among a random sample of 3,151 HIV-infected patients aged 21 years or older and diagnosed HIV-positive for at least three months. The EVAL survey took place in 27 HIV care centers located in the 6 of the 10 provinces of Cameroon where the ART scaling-up program was the most advanced (Centre, Littoral, West, South-West, North-West and FarNorth). Criteria for selection of the participating care centers included the size of the HIV caseload and the experience in the management of HIV infection (number of years of activity). During the survey, clinical data were collected using medical questionnaires filled in by care providers. Socio-demographic, economic and psychosocial data were collected during face-to-face interviews of patients performed by trained interviewers. The complete design of the survey is detailed elsewhere (Marcellin, Boyer et al. 2008). Our analyses were restricted to

\footnotetext{
${ }^{2}$ The EVAL survey is a research project which aims at evaluating the Cameroonian national program for improving access to ART. It was funded by the French National Agency for Research on AIDS and viral hepatitis (ANRS) and approved by the Ministry of Public Health in Cameroon and the Cameroonian National Ethics Committee.
} 
fertile women of reproductive age ( $<50$ years old) who participated in EVAL and were receiving ART at the time of the survey.

\section{Definition of the desire for a child}

Face-to-face interviews of women included one question about their desire for a child, with the following possible responses: (1) yes, I wish I will have a/another child (2) no, I do not want a/another child (3) I am pregnant (4) I cannot have a/another child (infertility, menopause ... etc). In this study, women who answered (1) or (3) were considered as reporting the desire to have a child. Women who answered (4) were excluded from the analyses. Assuming that some of these pregnancies may have been unwanted, we excluded pregnant women from the analysis.

\section{Variables}

Variables included in the analyses concerned the following domains: motherhood and sexual activity (age, matrimonial status, number of biological children, frequency of sexual relationships, use of contraception); social relationships (disclosure of seropositivity to the main partner, moral support from the family and/or the main partner); socio-economic status (educational level, area of habitation, being the head of the household, number of adults and children composing the household, number of persons contributing to the household income, professional status, monthly income of the household); clinical characteristics (time since HIV diagnosis, occurrence of diagnosis during pregnancy, CD4 count at last assessment and at initiation of ART, CDC clinical stage); experience with ART (time since initiation of ART, number of self-reported symptoms during the previous four weeks); self-reported physical and mental health-related quality of life (HRQL). Finally, women's knowledge and beliefs about HIV and ART were also considered, using three questions concerning the origin of the 
disease, six questions concerning the modes of transmission of HIV and five questions concerning the mechanisms of action of antiretroviral drugs. Indeed, we hypothesized that they might have an influence on women's perception of their disease, and in turn on their perception of their life in the future. Self-reported symptoms were collected using a 27 -item list, which was based on the self-completed HIV symptom index developed by Justice et al. (Justice, Holmes et al. 2001), and included 18 general symptoms often observed during ART (nausea, vomiting, burning in the stomach, stomach pain, change in the taste of food, bladder or kidney stones, diarrhoea, headache, fatigue, fever, difficulty falling or staying asleep, tickling around the mouth, aching muscles, aching feet and legs (neuropathy), itching skin, hallucinations or dizziness, problems having sexual intercourse and hair or fingernails problems) (Carrieri, Leport et al. 2006) and nine other symptoms related to lipodystrophy (change in overall body shape, hollow cheeks, larger belly or wider waist, slimmer arms, slimmer buttocks, slimmer legs, veins on the legs becoming visible, larger breasts, accumulation of fat in the neck) (Duran, Saves et al. 2001). HRQL was assessed using the Medical Outcome Study 12-item Short-Form Health Survey (SF-12 ${ }^{\circledR}$ ) (Ware, Kosinski et al. 1996; Ware, Kosinski et al. 2002), which explores both physical and mental components of HRQL and enables the calculation of the following two global scores: the physical component summary (PCS) and the mental component summary (MCS). These two scores range from 0 to 100 , a higher score value denoting a better HRQL.

\section{Statistical analysis}

Three aggregate scores were calculated to sum up the information concerning women's knowledge and beliefs about the origin of the HIV disease (score ranging from 0 to 3 ), the modes of transmission of HIV (score ranging from 0 to 6), and finally the mechanisms of action of antiretrovirals (ARVs) (score ranging from 0 to 5). To this end, correct answers were 
rated 1, while incorrect or "do not know" answers were rated 0 . These rates were then added to obtain the aggregate scores. Higher scores denote better knowledge. Factors associated with the desire for a child were explored using logistic regression models. Each factor was first tested for its association with the desire for a child in a univariate model, excluding categorical variables with classes concerning less than $5 \%$ of individuals. Factors with a pvalue $<0.25$ in these models were then included in a multivariate analysis. Time since HIV diagnosis and the number of children in the household were not included in the multivariate model due to their strong correlation with time since ART initiation and the number of biological children, respectively. In addition, aggregate scores were entered in the multivariate model, preferably to separate variables for knowledge and beliefs about HIV and ART. A forward stepwise selection procedure was used to determine the final multivariate model (entry threshold at $\mathrm{p}=0.05$ ). The significance level was fixed at $\alpha=0.05$ for all tests. The SPSS version 14.0 (SPSS Inc, Chicago, Illinois, USA) and SAS version 9.1 (SAS Institute Inc., Cary, NC, USA) for Windows software were used for the analyses.

\section{RESULTS}

\section{Characteristics of ART-treated fertile women of reproductive age}

A total of 2,466 patients included in EVAL were receiving ART at the time of the survey, of whom 1,746 were women. Among these women, 234 reported the inability to have children, 55 were more than 50 years old, 23 were pregnant and one had missing data concerning the desire for a child. Analyses were thus restricted to the remaining 1,433 ART-treated fertile women of reproductive age.

(Table 1 about here)

Median age [interquartile range 25\%; 75\%, IQR] was 33 [29; 39] years in this population (Table 1), with a minimum of 21 years old and a maximum of 49 years old. About 
four women in ten reported they were living in a couple, $26 \%$ were married, and half of those included had at least two biological children. Only $19 \%$ reported both having sexual relationships and not using contraception. Among sexually active women who reported using contraception, the methods most often chosen were condoms (91\% of women) and sexual abstinence or the withdrawal method (15\% of women) (not shown in the table). The other methods (birth control pill, implant, traditional methods) were rarely reported. Only 24\% percent of women reported at least two sexual relationships per month, and $40 \%$ had disclosed their seropositivity to their main partner.

Regarding socio-economic status, the vast majority of women in the study (79\%) lived in an urban or semi-urban area. Forty-one percent reported being the head of their household, and among these nine in ten reported being the only person to contribute to the household income (not shown in the table). Half of all the women in the analyses had been diagnosed HIV-positive at least 22 months previous to the study, and HIV diagnosis had occurred during pregnancy for $11 \%$ of women. Thirty-seven percent of women had experienced AIDSdefining events (CDC stage C). Women had been receiving ART for 14.7 [7.0; 25.9] months in median [IQR]. Finally, women reported having a median of 6 [3;9] symptoms during the previous four weeks. Fatigue and headache were the general symptoms most often reported (with $59 \%$ and $52 \%$ of women concerned, respectively), while change in overall body shape and larger belly or wider waist were the lipodystrophy-related symptoms most often reported (with $40 \%$ and $22 \%$ of women concerned, respectively) (not shown in the table). In addition, more than nine in ten had physical and mental HRQL score values above 25 , on a scale from 0 to 100.

(Table 2 about here)

Nearly all women were aware of the viral origin of HIV, knew about the main transmission modes (unprotected sexual relationships, blood transfusion) and the ability of 
antiretrovirals (ARV) to stabilise the development of the disease (Table 2). In addition, more than eight in ten reported they knew that babies from seropositive women could be infected during pregnancy or delivery, that one could not be infected when drinking from the same glass as a seropositive person, that ARV decrease the risk of becoming ill, and that ARV cannot be stopped even when a treated person feels better. However, only four women in ten knew that ARV cannot cure HIV. Women's positions also varied when asked different questions about poverty and supernatural forces as possible causes of HIV as well as the risk of being infected after a mosquito bite or when kissing a seropositive person. Finally, $11 \%$ of women thought that a person who takes ARV cannot transmit the virus.

\section{Factors associated with women's desire for a child}

(Table 3 about here)

A total of 791 women $(55 \%)$ reported the desire for a child.

In the univariate analyses, the following factors were significantly associated with the desire for a child: younger age, being married or in a free union, reporting at least two sexual relationships per month, having disclosed seropositivity to one's main partner, feeling supported by one's family or main partner, and having a low number of biological children (Table 3). Univariate analyses also identified the following socio-economic correlates of the desire for a child: women's educational level (high school or university); area of habitation (urban or semi-urban); social status (not being the head of the household; being professionally inactive); household characteristics (high monthly income with at least two persons contributing; having a low number of children in the household). Concerning clinical characteristics and women's perception of their health status, the following were also significantly associated with desire for a child: more recent HIV diagnosis, more recent ART initiation, low CD4 count at ART initiation $(<200$ cells/mm3) and good physical HRQL. In 
addition, women who had been diagnosed HIV-positive during pregnancy tended to report desire for a child more often than the others, but this association did not reach statistical significance $(\mathrm{p}=0.13)$. Finally, women with incomplete knowledge or erroneous beliefs about HIV and ART (whatever the question considered) reported the desire for a child significantly less often than the others. No significant relationship was detected between the desire for a child and the following factors: CDC stage $\mathrm{C}(\mathrm{p}=0.37), \mathrm{CD} 4$ count at last assessment, hospitalization during the previous six months, number of self-reported symptoms and level of mental HRQL ( $\mathrm{p}>0.25$, results not shown).

Multivariate analysis confirmed age, matrimonial status, number of biological children, frequency of sexual relationships, CD4 count at ART initiation and physical HRQL as independent determinants of women's desire for a child. In addition, a good knowledge about the origin of the HIV disease was also found to be independently associated with women's desire for a child.

\section{DISCUSSION}

In this study conducted in Cameroon in 2007 among 1,456 ART-treated fertile WLHA of reproductive age, more than half of the women reported they wished to have a/another child in the future. While estimates of the prevalence for the desire to have a child vary greatly from one study conducted in resource-limited settings to another (Myer, Morroni et al. 2007; Tamene and Fantahun 2007; Kaida, Maier et al. 2008; Mokgatle-Nthabu, Chinkanda et al. 2008), all conclude that a strong desire to have a child exists among ART-treated WLHA. . .

In the present study, no significant relationship was found between women's desire for a child and any of the factors related to their clinical status at the time of the survey, which echoes evidence already found in developed countries(Chen, Philips et al. 2001; Heard, Sitta 
et al. 2007; Nobrega, Oliveira et al. 2007). By contrast, women's perception of their physical HRQL together with low CD4 level at ART initiation both act as independent correlates of women's desire for a child. These very interesting findings suggest, on the one hand, that reproductive intentions are more strongly influenced by one's subjective health status than by one's objective clinical status (Chen, Philips et al. 2001). On the other hand, women with the most advanced immunodeficiency at treatment initiation may have delayed their pregnancy for health reasons; then, once recovered thanks to ART, may have regained enough confidence in the future to be able to think about positive personal projects, such as pregnancy. This result was partly confirmed by the fact that CD4 level at the time of the survey was not significantly associated with the outcome (result not shown), which suggests that it is a history of severe immunosuppression followed by a substantial recovery rather than the only immunological response to treatment that is likely to revivify WLHA's desire for a child. In poor as in high-resource settings, the shock of HIV diagnosis has disastrous consequences on a woman's life plans. In a recent study in Malawi, Hoffmann et al (Hoffman, Martinson et al. 2008) compared women's report of the desire for children before and after discovering their HIV serostatus, and analyzed the evolution of this desire over the twelve months following diagnosis. Results showed a sharp decline in the percentage of women reporting the desire to have a child, from $33 \%$ before diagnosis to $15 \%$ one week after. No significant change was observed thereafter, which however needs to be paralleled with the relatively short duration of follow-up, and with the fact that only $26 \%$ of women in the study initiated ART during follow-up. ART has a positive effect on WLHA's reproductive desires, something which has been highlighted notably by the work of Kaida et al. in the poorresource setting of Uganda. On the basis of data from a cross-sectional survey among 501 adult women aged less than 50 years attending an HIV clinic in that country, they found that women on ART, who represented $45 \%$ of their sample, were three times more likely to 
express fertility desires compared with ART-naïve women (Kaida, Maier et al. 2008). Using a scale including 23 statements about ART, concern about HIV infection, and concern about transmission to both sexual partners and unborn children during pregnancy, they also showed that women who reported that they desired (additional) children had significantly higher ART optimism scores than women who did not (Kaida, Diaz Lima et al. 2008).

The present study also confirms that WLHA who report desire for a child in poorresource settings are younger (Oladapo, Daniel et al. 2005; Peltzer, Chao et al. 2008) and have fewer biological children (Mantell, Cooper et al. 2008) than those who do not. These two factors, related to women's reproductive potential, have already been identified as independent correlates of the desire to have a child in developed countries (Chen, Philips et al. 2001; Heard, Sitta et al. 2007; Nobrega, Oliveira et al. 2007; Ogilvie, Palepu et al. 2007; Paiva, Santos et al. 2007). Not surprisingly in our study, women who were living in a couple and those who reported more frequent sexual relationships were significantly more likely to report the desire to have a child than the others.

Results also showed that better knowledge about HIV was associated with more frequent report of the desire to have a child, which suggests that women who received information about the disease were better armed to face it. At this point, it must be noted that nearly all women in the present study had integrated fundamental information about HIV. Indeed, more than nine women in ten knew about the viral origin of the disease, its main transmission modes (through blood and sexual fluids), the ability of ART to stabilise the development of the disease, and finally, the risk of mother-to-child HIV transmission. Although this constitutes a very encouraging outcome for the information campaigns conducted in Cameroon, there is still much work to do, as some erroneous beliefs go on coexisting with correct basic knowledge and turn out to be detrimental for women's life plans. These are mainly either deeply ingrained popular beliefs (such as belief in the influence of 
spirits or supernatural forces) or widespread rumour, closely related to both the fear of getting infected and the stigmatization of infected individuals (such as believing that HIV can be transmitted through saliva). In addition, some women still perceive ARV as a curative therapy. These findings highlight the need for developing information and counselling actions on HIV and ART on a regular basis during the follow-up of WLHA, while most information actions are currently conducted at the time of HIV diagnosis and at initiation of ART. These actions should be tailored to the African socio-cultural context. The power of rumour and gossip must be taken into account and used to counteract the distrust and resistance to more formal channels of communication: for instance, community radio broadcasts can be effectively used to spark rumours about HIV containing positive prevention messages (Stadler 2003). In addition, prevention from peers should be maintained and reinforced in HIV care centers, as well as the involvement of HIV-infected people associations in the follow-up of WLHA, in order to pursue the fight against HIV stigma.

Finally, results confirmed that women's educational and economic status, and area of residence (urban versus rural) affect their intentions to have a child (Nebie, Meda et al. 2001; Desgrees-Du-Lou, Msellati et al. 2002; Hoffman, Martinson et al. 2008), although these factors were no more significant in the multivariate analysis. Economic factors such as the level of income of the household have also been shown to play a key role in the fertility intentions of women who are not HIV-infected, notably in Eastern Europe and Asia (Mahmood 1992; Ranjan 1999).

In the same way, disclosure of HIV status to one's main partner and support from the family or one's main partner (Kanniappan, Jeyapaul et al. 2008) were both associated with women's desire for a child, but only in univariate analyses.

Limitations of the present study include its cross-sectional design, which does not allow analysis of the longitudinal changes in women's desire for a child. There is also a lack 
of data concerning women's knowledge and access to Prevention of Mother-To-Child Transmission (PMTCT) programs, which may affect their reproductive intentions (Kanniappan, Jeyapaul et al. 2008; Peltzer, Chao et al. 2008). In addition, it must be noted that the categories in the outcome variable are not mutually exclusive. In particular, a woman who is infertile could wish to have a child. However, for a purpose of homogeneity of the study population, the aim of our analysis was to explore the determinants of the desire for a child exclusively among fertile women. In this context, the use of a close question to assess women's desire for a child, without allowing multiple answers, was a deliberate choice. Finally, the present study is also limited by the lack of information concerning desire for a child among pregnant women $(n=23)$, who were thus excluded from the analyses.

\section{CONCLUSION}

The desire to have a child is frequent among ART-treated WLHA of reproductive age in Cameroon. Apart from women's reproductive potential (younger age, living in a couple, already being a mother, having frequent sexual relationships), the correlates of this desire comprise, on the one hand, the experience of the HIV disease, through past immunodeficiency and perception of physical HRQL at the time of the survey; and, on the other hand, a good knowledge of HIV and ART. In a national context of the scaling-up of ART, these data suggest that HIV care and family planning programs should be better integrated in order to support WLHA's reproductive choices. Counselling and information actions should be developed on a regular basis throughout women's follow-up. Future prevention strategies should consider alternative channels of communication and should further encourage the involvement of peers in order to support WLHA who desire children and to maximise their chances to live a healthy pregnancy and to give birth to a HIV-negative baby. 


\section{ACKNOWLEDGEMENTS}

We would like to thank the French National Agency for Research on AIDS and viral hepatitis (ANRS) which funded this research and the Cameroonian Ministry of Health for its support in the implementation of the EVAL survey. We would also like to thank all the patients who accepted to participate in the survey as well as healthcare providers for their strong involvement in the data collection stage.

\section{DISCLOSURE OF INTERESTS}

There is no conflict of interest.

\section{DETAILS OF ETHICS APPROVAL}

The research was approved by the Ministry of Public Health in Cameroon and the Cameroonian National Ethics Committee.

\section{FUNDING}

The French National Agency for Research on AIDS and viral hepatitis (ANRS) funded the EVAL survey (ANRS 12-116) research program and the Cameroonian Ministry of Public Health supported its execution. 


\section{REFERENCES}

(2008). "United Nations Statistics Division - Millennium Development Goals Database."

Aka Dago-Akribi, H., P. Msellati, et al. (2001). "Procreation and Child Desire of Women living with HIV in Abidjan, Côte d'Ivoire." Psychological, Health \& Medicine 6(3): pp 283- 291.

Bungener, C., N. Marchand-Gonod, et al. (2000). "African and European HIV-positive women: psychological and psychosocial differences." AIDS Care 12(5): 541-8.

Carrieri, M. P., C. Leport, et al. (2006). "Factors associated with nonadherence to highly active antiretroviral therapy: a 5-year follow-up analysis with correction for the bias induced by missing data in the treatment maintenance phase." J Acquir Immune Defic Syndr 41(4): 477-85.

Chama, C., J. Morrupa, et al. (2007). "Sex and reproduction among HIV-infected people in Maiduguri, Nigeria." J Obstet Gynaecol 27(8): 812-5.

Chen, J. L., K. A. Philips, et al. (2001). "Fertility desires and intentions of HIV-positive men and women." Fam Plann Perspect 33(4): 144-52, 165.

Desclaux, A. and A. Desgrées du Loû (2006). "Les femmes africaines face à l'épidémie de sida." Population et sociétés 428.

Desgrees-Du-Lou, A., P. Msellati, et al. (2002). "Contraceptive use, protected sexual intercourse and incidence of pregnancies among African HIV-infected women. DITRAME ANRS 049 Project, Abidjan 1995-2000." Int J STD AIDS 13(7): 462-8.

Desgrées du Loû, A. and B. Ferry (2005). "Sexualité et procréation face aux risques du Sida Permanences et adaptations dans les pays fortement touchés par l'épidémie." La Chronique CEPED 49.

Desgrées du Loû , A. and B. Ferry (2006). Sexualité et procréation confrontées au sida dans les pays du Sud. Les Collections du Ceped, Paris.

Desgrees du Loû, A., P. Msellati, et al. (1999). "Le recours à l'avortement provoqué à Abidjan. Une cause de la baisse de la fécondité?" Population 54: pp 427- 446.

Duran, S., M. Saves, et al. (2001). "Failure to maintain long-term adherence to highly active antiretroviral therapy: the role of lipodystrophy." Aids 15(18): 2441-4.

Heard, I., R. Sitta, et al. (2007). "Reproductive choice in men and women living with HIV: evidence from a large representative sample of outpatients attending French hospitals (ANRS-EN12-VESPA Study)." Aids 21 Suppl 1: S77-82.

Hoffman, I. F., F. E. Martinson, et al. (2008). "The year-long effect of HIV-positive test results on pregnancy intentions, contraceptive use, and pregnancy incidence among Malawian women." J Acquir Immune Defic Syndr 47(4): 477-83.

Justice, A. C., W. Holmes, et al. (2001). "Development and validation of a self-completed HIV symptom index." J Clin Epidemiol 54 Suppl 1: S77-90.

Kaida, A., V. Diaz Lima, et al. (2008). The WHOMEN's scale (Women's HAART Optimism Monitoring and EvaluatioN scale v.1) and the association with increased fertility desires among HIV-positive women in Uganda. XVII International AIDS Conference (abstract $\mathrm{n}^{\circ}$ WEPE0308), Mexico City.

Kaida, A., M. Maier, et al. (2008). Use of antiretroviral therapy is associated with increased fertility desires but decreased likelihood of pregnancy and livebirth among HIVpositive women in Mbarara, Uganda. XVII International AIDS Conference (abstract $\mathrm{n}^{\circ}$ TUPE0918), Mexico City.

Kanniappan, S., M. J. Jeyapaul, et al. (2008). "Desire for motherhood: exploring HIV-positive women's desires, intentions and decision-making in attaining motherhood." $\underline{\text { AIDS }}$ Care 20(6): 625-30. 
Mahmood, N. (1992). "The desire for additional children among Pakistani women: the determinants." Pak Dev Rev 31(1): 1-30.

Mantell, J. E., D. Cooper, et al. (2008). Toward improved reproductive health choices and health care delivery for HIV-infected men and women in developing countries with generalised HIV epidemics. XVII International AIDS Conference (abstract $\mathrm{n}^{\circ}$ MOAD02), Mexico City.

Marcellin, F., S. Boyer, et al. (2008). "Determinants of unplanned antiretroviral treatment interruptions among people living with HIV in Yaounde, Cameroon (EVAL survey, ANRS 12-116)." Trop Med Int Health 13(12): 1470-8.

Mokgatle-Nthabu, M., N. Chinkanda, et al. (2008). HIV positive women's perception of mother to child transmission and the desire to bear children: implications for HIV prevention. XVII International AIDS Conference (abstract $n^{\circ}$ TUPDD103), Mexico City.

Myer, L., C. Morroni, et al. (2007). "Prevalence and determinants of fertility intentions of HIV-infected women and men receiving antiretroviral therapy in South Africa." AIDS Patient Care STDS 21(4): 278-85.

National AIDS Control Committee, C. T. G., Permanent Secretariat, Ministry of Public Health (2007). Towards universal access to treatment and care for adults and children living with HIV/AIDS in Cameroon. Progress report $N^{\circ} 7$, National AIDS Control Committee / Ministry of Public Health.

Nebie, Y., N. Meda, et al. (2001). "Sexual and reproductive life of women informed of their HIV seropositivity: a prospective cohort study in Burkina Faso." J Acquir Immune Defic Syndr 28(4): 367-72.

Nobrega, A. A., F. A. Oliveira, et al. (2007). "Desire for a child among women living with HIV/AIDS in northeast Brazil." AIDS Patient Care STDS 21(4): 261-7.

Ogilvie, G. S., A. Palepu, et al. (2007). "Fertility intentions of women of reproductive age living with HIV in British Columbia, Canada." Aids 21 Suppl 1: S83-8.

Oladapo, O. T., O. J. Daniel, et al. (2005). "Fertility desires and intentions of HIV-positive patients at a suburban specialist center." J Natl Med Assoc 97(12): 1672-81.

Paiva, V., N. Santos, et al. (2007). "Desire to have children: gender and reproductive rights of men and women living with HIV: a challenge to health care in Brazil." AIDS Patient Care STDS 21(4): 268-77.

Peltzer, K., L. W. Chao, et al. (2008). "Family Planning Among HIV Positive and Negative Prevention of Mother to Child Transmission (PMTCT) Clients in a Resource Poor Setting in South Africa." AIDS Behav.

Ranjan, P. (1999). "Fertility behaviour under income uncertainty." Eur J Popul 15(1): 25-43.

Stadler, J. (2003). "Rumor, gossip and blame: implications for HIV/AIDS prevention in the South African lowveld." AIDS Educ Prev 15(4): 357-68.

Tamene, W. and M. Fantahun (2007). "Fertility desire and family-planning demand among HIV-positive women and men undergoing antiretroviral treatment in Addis Ababa, Ethiopia." African Journal of AIDS Research 6(3): 223-227.

UNAIDS (2008). Report on the global AIDS epidemic.

UNAIDS and WHO (2007). AIDS epidemic update, Joint United Nations Programme on HIV/AIDS (UNAIDS) and World Health Organization (WHO)

Ware, J., Jr., M. Kosinski, et al. (1996). "A 12-Item Short-Form Health Survey: construction of scales and preliminary tests of reliability and validity." Med Care 34(3): 220-33.

Ware, J. E., M. Kosinski, et al. (2002). SF-12v2: How to Score Version 2 of the SF-12 Health Survey, Lincoln, RI: QualityMetric.

WHO-UNAIDS (2008). Epidemiological Fact Sheet on HIV and AIDS - Cameroon. 
Table 1 - Characteristics of ART-treated fertile women of reproductive age included in

the EVAL survey in Cameroon $(n=1,433)$

\begin{tabular}{|c|c|}
\hline & $\begin{array}{c}\% \text { of women } \\
\text { or median [IQR] }\end{array}$ \\
\hline \multicolumn{2}{|l|}{ Motherhood, sexual activity and social relationships } \\
\hline Age - years & $33[29 ; 39]$ \\
\hline \multicolumn{2}{|l|}{ Matrimonial status } \\
\hline - single, widowed or divorced & 62.0 \\
\hline - married & 26.3 \\
\hline - free union, or stable relationship & 11.7 \\
\hline No. of biological children & $2[1 ; 3]$ \\
\hline \multicolumn{2}{|l|}{ Frequency of sexual relationships } \\
\hline - once a month or less & 76.4 \\
\hline - at least twice a month & 23.6 \\
\hline \multicolumn{2}{|l|}{ Use of contraception } \\
\hline - no sexual relationships & 39.8 \\
\hline - no use of contraception & 19.7 \\
\hline - use of contraception & 40.5 \\
\hline \multicolumn{2}{|l|}{ Disclosure of seropositivity to main partner } \\
\hline - no disclosure (or no main partner) & 59.7 \\
\hline - disclosure to a seropositive partner & 10.3 \\
\hline $\begin{array}{l}\text { - disclosure to a seronegative or unknown HIV } \\
\text { status partner }\end{array}$ & 30.0 \\
\hline \multicolumn{2}{|l|}{ Support from the family and/or main partner } \\
\hline- no & 27.4 \\
\hline - yes & 72.6 \\
\hline \multicolumn{2}{|l|}{ Socio-economic status } \\
\hline \multicolumn{2}{|l|}{ Educational level } \\
\hline - primary school & 41.0 \\
\hline - high school or university & 59.0 \\
\hline \multicolumn{2}{|l|}{ Area of habitation } \\
\hline - urban or semi-urban & 79.5 \\
\hline - rural & 20.5 \\
\hline \multicolumn{2}{|l|}{ Being the head of the household } \\
\hline - no & 58.9 \\
\hline - yes & 41.1 \\
\hline No. of adults in the household & $3[2 ; 4]$ \\
\hline No. of children in the household & $2[1 ; 4]$ \\
\hline \multicolumn{2}{|l|}{ No. of persons contributing to the household income } \\
\hline-1 person & 67.5 \\
\hline - 2 persons or more & 32.5 \\
\hline \multicolumn{2}{|l|}{ Professional status } \\
\hline - inactive & 33.4 \\
\hline - active & 66.6 \\
\hline Monthly income of the household $\times 1000 \mathrm{~F} \mathrm{CFA}$ & $36.9[21.6 ; 60.0]$ \\
\hline \multicolumn{2}{|l|}{ Clinical characteristics } \\
\hline \multicolumn{2}{|l|}{ CD4 count - cells $/ \mathrm{mm}^{3}$} \\
\hline - at last assessment & $321[222 ; 457]$ \\
\hline $\begin{array}{l}\text { - at initiation of ART } \\
\quad<200\end{array}$ & $124[62 ; 177]$ \\
\hline
\end{tabular}




\begin{tabular}{lc}
\hline - no & 18.6 \\
$\quad$ - yes & 81.4 \\
CDC stage C & \\
- no & 62.7 \\
- yes & 37.3 \\
Hospitalised during the previous 6 months & \\
- no & 87.9 \\
- yes, at least once & 12.1 \\
\hline Experience with ART & \\
Time since initiation of ART - months $^{1}$ & $14.7[7.0 ; 25.9]$ \\
Total no. of self-reported symptoms & $6[3 ; 9]$ \\
No. of general symptoms ${ }^{1}$ & $5[3 ; 7]$ \\
No. of lipodystrophy symptoms ${ }^{1}$ & $1[0 ; 3]$ \\
\hline Health-related quality of life & \\
Physical score (PCS) & $52[45 ; 56]$ \\
Mental score (MCS) & $43[37 ; 50]$ \\
\hline Diagnosed HIV-positive during pregnancy & \\
- no & 89.2 \\
- yes & 10.8 \\
\hline
\end{tabular}

$\mathrm{SD}=$ standard deviation; $\mathrm{IQR}=$ interquartile range $[25 \% ; 75 \%]$

${ }^{1}$ during the previous 4 weeks - general symptoms: nausea, vomiting, burning in the stomach, stomach pain, change in the taste of food, bladder or kidney stones, diarrhoea, headache, fatigue, fever, difficulty falling or staying asleep, tickling around the mouth, aching muscles, aching feet and legs (neuropathy), itching skin, hallucinations or dizziness, problems having sexual intercourse and hair or fingernails problems - lipodystrophy symptoms: change in overall body shape, hollow cheeks, larger belly or wider waist, slimmer arms, slimmer buttocks, slimmer legs, veins on the legs becoming visible, larger breasts, accumulation of fat in the neck. 
Table 2 - Knowledge and beliefs about HIV and ART among ART-treated fertile women of reproductive age included in the EVAL survey in Cameroon $(n=1,433)$

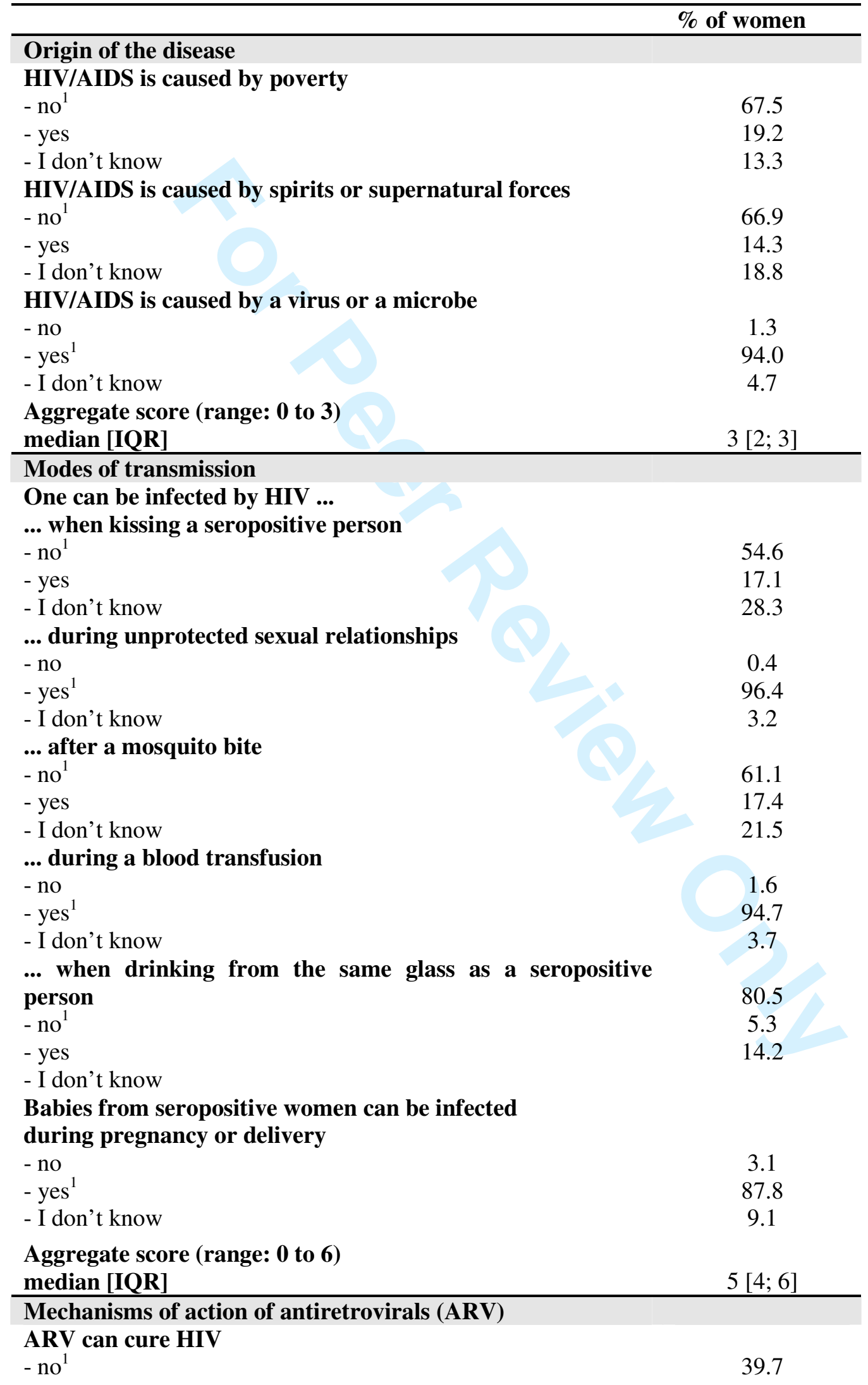


- yes

33.8

- I don't know

ARV stabilise the development of HIV

0.8

- no

92.8

- yes

6.3

ARV decrease the risk of becoming ill

- no

- yes $^{1}$

83.9

- I don't know

8.0

A person who takes ARV cannot transmit HIV

- no ${ }^{1}$

68.9

- yes

11.1

- I don't know

20.0

A person who takes ARV and feels better can stop treatment

- no $^{1}$

87.0

- yes

3.3

- I don't know

9.7

Aggregate score (range: 0 to 5)

median [IQR]

$4[3 ; 5]$ 
$\mathrm{IQR}=$ interquartile range

${ }^{1}$ correct answer. 
Table 3 - Factors associated with desire for a child among ART-treated fertile women of reproductive age included in the EVAL survey in Cameroon

\begin{tabular}{|c|c|c|c|c|}
\hline & \multicolumn{2}{|c|}{ Univariate analyses } & \multicolumn{2}{|c|}{ Multivariate analysis } \\
\hline & p-value & OR $[95 \% \mathrm{CI}]$ & p-value & OR $[95 \% \mathrm{CI}]$ \\
\hline \multicolumn{5}{|l|}{ Motherhood, sexual activity and social relationships } \\
\hline \multirow{2}{*}{\multicolumn{5}{|c|}{ Matrimonial status* }} \\
\hline & & & & \\
\hline - single, widowed or divorced (ref.) & $<0.0001$ & 1 & $<0.0001$ & 1 \\
\hline - married & & $1.13[0.89 ; 1.44]$ & & $1.94[1.37 ; 2.73]$ \\
\hline - free union, or stable relationship & & $2.82[1.95 ; 4.07]$ & & $2.03[1.29 ; 3.19]$ \\
\hline No. of biological children* & $<0.0001$ & $0.42[0.39 ; 0.47]$ & $<0.0001$ & $0.46[0.41 ; 0.51]$ \\
\hline \multicolumn{5}{|l|}{ Frequency of sexual relationships* } \\
\hline - once a month or less (ref.) & $<0.0001$ & 1 & 0.0001 & 1 \\
\hline - at least twice a month & & $2.13[1.65 ; 2.75]$ & & $1.96[1.38 ; 2.77]$ \\
\hline \multicolumn{5}{|l|}{ Disclosure of seropositivity to main partner* } \\
\hline - no disclosure (or no main partner) (ref.) & 0.0096 & 1 & & \\
\hline - disclosure to a seropositive partner & & $1.22[0.861 .74]$ & & \\
\hline - disclosure to a seronegative or unknown HIV status partner & & $1.43[1.13 ; 1.81]$ & & \\
\hline \multicolumn{5}{|l|}{ Support from the family and/or main partner* } \\
\hline - no (ref.) & 0.0009 & 1 & & \\
\hline - yes & & $1.49[1.18 ; 1.88]$ & & \\
\hline \multicolumn{5}{|l|}{ Socio-economic status } \\
\hline Educational level* & 3 & & & \\
\hline - primary school (ref.) & $<0.0001$ & 1 & & \\
\hline - high school or university & & $2.39[1.92 ; 2.96]$ & & \\
\hline \multicolumn{5}{|l|}{ Area of habitation* } \\
\hline - urban or semi-urban (ref.) & 0.007 & 1 & & \\
\hline - rural & & $0.70[0.54 ; 0.91]$ & & \\
\hline \multicolumn{5}{|l|}{ Being the head of the household* } \\
\hline - no (ref.) & $<0.0001$ & 1 & & \\
\hline - yes & & $0.40[0.32 ; 0.49]$ & & \\
\hline No. of children in the household & $<0.0001$ & $0.88[0.84 ; 0.92]$ & & \\
\hline \multicolumn{5}{|l|}{$\begin{array}{l}\text { No. of persons contributing } \\
\text { to the household income* }\end{array}$} \\
\hline - 1 person (ref.) & 0.014 & 1 & & \\
\hline - 2 persons or more & & $1.32[1.06 ; 1.65]$ & & \\
\hline \multicolumn{5}{|l|}{ Professional status* } \\
\hline - inactive (ref.) & 0.004 & 1 & & \\
\hline - active & & $0.72[0.58 ; 0.90]$ & & \\
\hline \multicolumn{5}{|l|}{ Monthly income of the household* } \\
\hline - OR for a $1 \log _{10}$ increment & 0.01 & $1.40[1.08 ; 1.81]$ & & \\
\hline \multicolumn{5}{|l|}{ Clinical characteristics } \\
\hline \multicolumn{5}{|l|}{ Time since HIV diagnosis } \\
\hline - OR for a 12-month increment & 0.02 & 0.995 [0.990; 0.999] & & \\
\hline \multicolumn{5}{|l|}{ CD4 count at initiation of ART $<200$ cells $/ \mathrm{mm}^{3} *$} \\
\hline - no (ref.) & 0.03 & 1 & 0.002 & 1 \\
\hline - yes & & $1.33[1.02 ; 1.74]$ & & $1.73[1.22 ; 2.44]$ \\
\hline \multicolumn{5}{|l|}{ CDC stage $C$} \\
\hline - no (ref.) & 0.37 & 1 & & \\
\hline - yes & & $0.91[0.73 ; 1.12]$ & & \\
\hline
\end{tabular}

Experience with ART 
Time since initiation of ART*

- OR for a 12-month increment

0.009

$0.90[0.83 ; 0.97]$

Health-related quality of life

Physical score (PCS)

$<0.0001$

$1.02[1.01 ; 1.04]$

0.012

$1.02[1.01 ; 1.03]$

Diagnosed HIV-positive during pregnancy*

- no (ref.)

0.13

1

$1.30[0.93 ; 1.82]$

Knowledge and beliefs about HIV and ART

Origin of the disease

HIV/AIDS is caused by poverty

- no $^{1}$ (ref.)

- yes/I don't know

$0.001-1$

HIV/AIDS is caused by spirits

or supernatural forces

- no ${ }^{1}$ (ref.)

$0.08-1$

- yes/I don't know

$0.82[0.66 ; 1.02]$

HIV/AIDS is caused by a virus or a microbe

- yes ${ }^{1}$ (ref.)

0.0002

$0.69[0.55 ; 0.86]$

- no/I don't know

Aggregate score - OR for a 1-point increment*

Modes of transmission

One can be infected by HIV ...

... when kissing a seropositive person

- no (ref.)

- yes/I don't know

$<0.0001 \quad 1$

... after a mosquito bite

- no ${ }^{1}$ (ref.)

$<0.0001-1$

- yes/I don't know

$0.63[0.51 ; 0.78]$

... when drinking from the same glass

as a seropositive person

- no $^{1}$ (ref.)

$\begin{array}{cc}<.0001 & 1 \\ 0.57[0.44 ; 0.74]\end{array}$

- yes/I don't know

Babies from seropositive women can be infected

during pregnancy or delivery

- yes $^{1}$ (ref.)

0.16

$0.42[0.26 ; 0.66]$

$<0.0001 \quad 1.28[1.13 ; 1.45]$

0.008

$1.24[1.06 ; 1.46]$

- no/ I don't know

$0.80[0.58 ; 1.09]$

Aggregate score - OR for a 1-point increment*

$<0.0001$

$1.27[1.17 ; 1.38]$

Mechanisms of action of ARV

ARV can cure HIV

- no $^{1}$ (ref.)

0.23

1

- yes/ I don't know

A person who takes ARV cannot transmit HIV

- no ${ }^{1}$ (ref.)

$0.88[0.71 ; 1.08]$

- yes/ I don't know

A person who takes ARV and feels better

can stop treatment

- no ${ }^{1}$ (ref.)

0.046

$0.73[0.54 ; 0.99]$

- yes/ I don't know

$1.12[1.02 ; 1.23]$

Aggregate score - OR for a 1-point increment*

0.017

$0.75[0.60 ; 0.94]$

$\mathrm{OR}=$ odd ratio $\mathrm{CI}=$ confidence interval $\mathrm{ART}=$ antiretroviral therapy; $\mathrm{ARV}=$ antiretroviral drugs

* variables entered in the multivariate analysis.

${ }^{1}$ correct answer. 